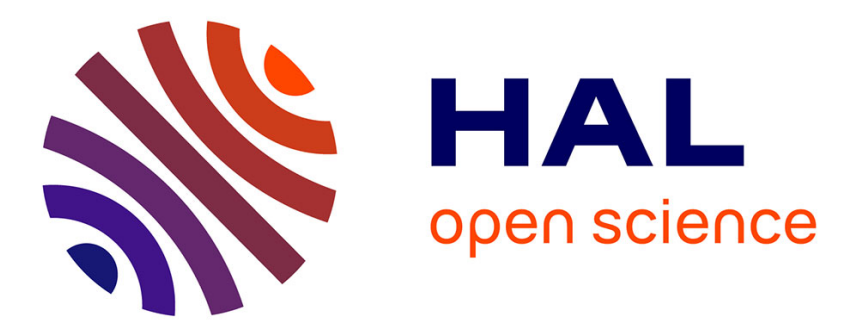

\title{
Imaging of an undulator source by phase circular Bragg-Fresnel lenses
}

\author{
Ya. Hartman, E. Tarazona, P. Elleaume, I. Snigireva, A. Snigirev
}

\section{To cite this version:}

Ya. Hartman, E. Tarazona, P. Elleaume, I. Snigireva, A. Snigirev. Imaging of an undulator source by phase circular Bragg-Fresnel lenses. Journal de Physique IV Proceedings, 1994, 04 (C9), pp.C9-45C9-48. 10.1051/jp4:1994907 . jpa-00253467

\section{HAL Id: jpa-00253467 https://hal.science/jpa-00253467}

Submitted on 1 Jan 1994

HAL is a multi-disciplinary open access archive for the deposit and dissemination of scientific research documents, whether they are published or not. The documents may come from teaching and research institutions in France or abroad, or from public or private research centers.
L'archive ouverte pluridisciplinaire HAL, est destinée au dépôt et à la diffusion de documents scientifiques de niveau recherche, publiés ou non, émanant des établissements d'enseignement et de recherche français ou étrangers, des laboratoires publics ou privés. 


\title{
Imaging of an undulator source by phase circular Bragg-Fresnel lenses
}

Ya. Hartman, E. Tarazona*, P. Elleaume*, I. Snigireva* and A. Snigirev*

Institute of Microelectronics Technology, Russian Academy of Sciences, 142432 Chernogolovka, Moscow district, Russia

* European Synchrotron Radiation Facility, BP. 220, 38043 Grenoble cedex, France

\begin{abstract}
Focusing properties and heatload resistance of a Bragg-Fresnel lens placed in an undulator beam have been demonstrated. The electron beam at an undulator source has been imaged by two setups using Bragg-Fresnel lenses. The first setup is a two-lenses telescope and the second one consists of one circular BFL and an asymmetrically cut crystal.
\end{abstract}

\section{INTRODUCTION}

Measuring the emittance of a third generation synchrotron radiation source is a non trivial problem. The conventional monitor based on visible light imaging is not well adapted to this purpose because of the small size of the source (FWHM=50 $\mu \mathrm{m}$ at the ESRF) and the high heatload which distorts the mirror. To avoid these difficulties, we used circular Bragg Fresnel Optics [1] (BFO) to obtain an $\mathrm{x}$ ray image of the source.

Three different experiments have been carried out. In the first experiment, the source was imaged through a single Bragg-Fresnel lens (BFL) on a Kodak high resolution film. In the second one, a telescope set-up has been used with imaging on a CCD camera. In the third one, a single BFL associated with an asymmetrically cut crystal have been used with the same CCD camera.

All experiments were carried out at the ESRF on the machine diagnostics beamline (ID6) whose source is a high beta undulator $\left(\beta_{\mathrm{X}}=27 \mathrm{~m}, \beta_{\mathrm{Z}}=13 \mathrm{~m}\right)$.

\section{SINGLE LENS EXPERIMENTS}

\subsection{Setup}

The undulator used presents 32 periods of $48 \mathrm{~mm}$ with a maximum magnetic field of $0.5 \mathrm{~T}$ corresponding to a maximum deflection parameter $\mathrm{K}=2.2$. In these experiments, the FWHM of the source was $800 \mu \mathrm{m}$ in the horizontal and $250 \mu \mathrm{m}$ in the vertical.

The circular BFL was manufactured on a Si-111 substrate. The basic geometrical parameters are: an innermost zone radius $\mathrm{r}_{1}=8.8 \mu \mathrm{m}$; an outermost zone width $\Delta \mathrm{r}_{\mathrm{n}}=0.4 \mu \mathrm{m}$; an aperture $\mathrm{A}=200 \mu \mathrm{m}$. The Si crystal was stuck with a GaIn contact layer on a small copper block without water cooling. The image was registered with a Kodak high resolution film placed at a variable distance from the BFL. 


\subsection{Heatload test}

In order to check whether the BFL could withstand the heatload caused by synchrotron radiation, we closed the undulator gap to its minimum value of $20 \mathrm{~mm}$. Then, the total incident power was around $100 \mathrm{~W}$ with a power density of $12 \mathrm{~W} / \mathrm{mm}^{2}$. The temperature of the crystal stabilized at around $420^{\circ} \mathrm{C}$. No significant changes in the optical properties of the BFL has been observed on the film exposed when the temperature has stabilized. An image done after cooling was identical to the one performed before the heatload experiment.

\subsection{Imaging for even and odd harmonics of the undulator}

Fig 1 shows the images obtained on the first order of Fresnel diffraction on the 555 Bragg peak $(\mathrm{E}=9.9 \mathrm{keV})$ for magnetic gaps of 35 and $25.2 \mathrm{~mm}$ corresponding respectively to the second and the third harmonic. While the image of the third harmonic is simple, the image of the second harmonic is split in two spots. This is due to the two lobes of emission of this harmonic as explained in Fig 1.

a)

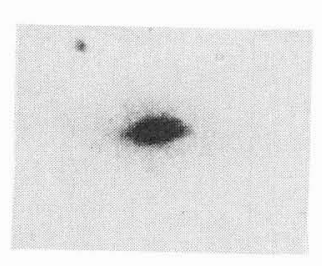

b)

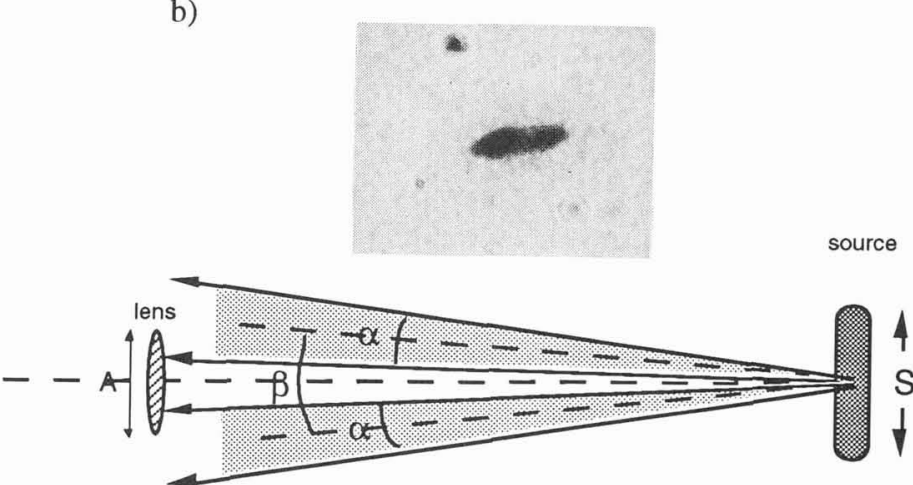

Fig.1 (a) Image recorded on the third harmonic. (b) Image recorded on the second harmonic. (c) Explanation of the split in the 2nd harmonic image: only the light emitted by the outer part of the source goes through the lens, the central part is not seen.

\section{HIGH ENERGY X-RAY TELESCOPE}

We used a $42 \mathrm{~mm}$-period undulator on the first harmonic (gap=45mm).

The high energy $x$-ray telescope setup based on two circular BFL is presented in Fig.2. We used $\mathrm{Si}-444$ reflection at the energy of $7.91 \mathrm{keV}$. Under such conditions, the Bragg angle was $88.5^{\circ}$. The main parameters of the objective and ocular BFLs are listed in Table 1.

Table 1. Main parameters of the objective and ocular BFLs.

\begin{tabular}{|c|c|c|c|c|c|c|c|}
\hline & $\mathrm{r} 1[\mu \mathrm{m}]$ & $\Delta \mathrm{r}_{\mathrm{n}}[\mu \mathrm{m}]$ & $\mathrm{f}[\mathrm{m}]$ & $\mathrm{A}[\mu \mathrm{m}]$ & phase shift $/ \pi$ & $\begin{array}{c}\text { 1st order } \\
\text { efficiency, \% }\end{array}$ & $\begin{array}{c}\text { 0th order } \\
\text { efficiency, } \%\end{array}$ \\
\hline BFL1 & 14 & 0.5 & 1.25 & 400 & 0.82 & 34 & 16 \\
\hline BFL2 & 6.2 & 0.3 & 0.25 & 128 & 0.75 & 30.9 & 23.9 \\
\hline
\end{tabular}


The magnification given by this system equals 0.2 . As it is shown in table 1 , the deviation of the phase shift from $\pi$ limits the efficiency of the first order of Fresnel diffraction and enhance the zeroth order (background). In order to decrease this background, we installed a $100 \mu \mathrm{m}$ diameter pinhole in the plane of the objective image. The size of the image recorded with the CCD camera, $140 \times 80 \mu \mathrm{m}^{2}$, was in good agreement with the size of the source estimated by other methods.

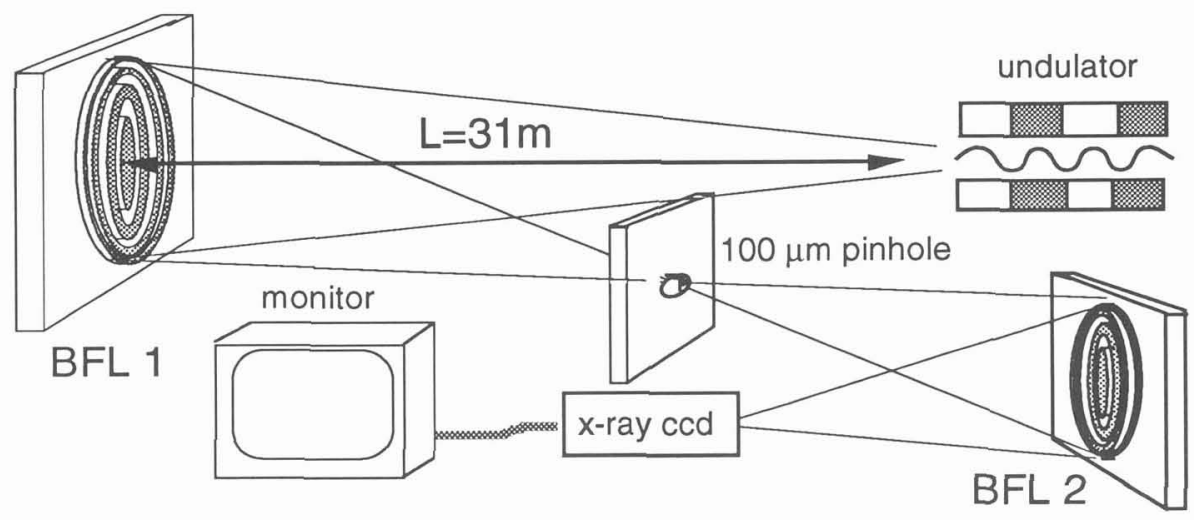

Fig.2 Schematic layout of the x-ray telescope.

\section{MAGNIFICATION BY AN ASYMMETRICALLY CUT CRYSTAL}

\subsection{Setup}

The previous setup allowed us to obtain a measure of both horizontal and vertical sizes of the source. However, it was difficult to adjust properly and very sensitive to thermal deformations on the first crystal. As the smaller size, and so the most difficult to measure, is the vertical one, we tested the following setup that allowed us to magnify only in the vertical direction. (Fig 3)

We used the third harmonic of the same undulator as in the single lens tests ( $g a p=23 \mathrm{~mm}$ ). The BFL was the one used as the objective of the telescope at the same energy. The asymmetrically cut crystal was a Si-422 with an asymmetry factor of 13.7 , placed in the objective plane.

It is interesting to point out that a partial elimination of the zeroth order of Fresnel diffraction is possible by rotating the asymmetric crystal slightly away from the Bragg condition by an angle nearly equal to the divergence of the focused beam.

\subsection{Measurements}

We tested this system in two situations. In the first (second) one, the vertical emittance was 1.1 (0.2) nm.rad, which corresponds to a source size of 280 (120) $\mu \mathrm{m}$ FWHM and to a full divergence of 30 (20) $\mu \mathrm{rad}$. The measured size was $50 \%$ (80\%) bigger than expected.

The images recorded at photon energies close to the top of the third harmonic presented a vertical splitting similar to the one observed previously in the horizontal plane for the second harmonic. The explanation for this splitting is again the presence of two vertical lobes, separated by $10-20 \mu \mathrm{rad}$. 
Therefore, a part of the disagreement between real and measured vertical source sizes can be accounted to this effect which originates from an imperfect setting of the photon energy.

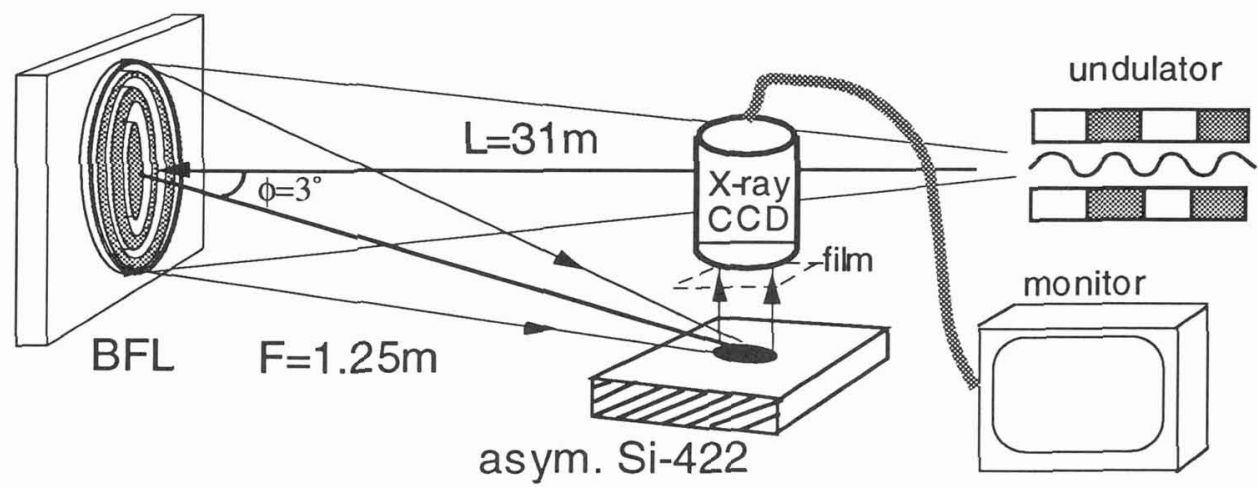

Fig. 3 Schematic layout of the BFL+asymmetric crystal setup.

\section{CONCLUSION}

These experiments showed that it is easy to focus an undulator $\mathrm{x}$-ray beam $(\lambda \sim 1 \AA)$ with a BraggFresnel lens. This was done with an incident power as high as $12 \mathrm{~W} / \mathrm{mm} 2$ without water cooling. The BFL withstood these conditions without any problem.

We also showed that the association of a BFL with another optics, BFL or asymmetrically cut crystal, doesn't alter its focusing properties.

We tried to apply these optics to a beam emittance monitor by imaging the source in the $\mathrm{x}$-ray range. The small aperture of the BFL associated with the angular diagram of emission of an undulator produced tricky effects which did not allow us to make reliable measurements. In any case, an enlargement of the BFLs aperture to $1 \mathrm{~mm}$ is expected in the coming years, which would perfectly fit the size of the central cone of an undulator and should solve most of the pending problems.

\section{Acknowledgment}

We wish to thank Daniel Häusermann for his support.

We are also very grateful to Dr. V. Yunkin and to Mrs. N. Gornakova (IMT) for the BFLs preparation.

\section{References}

[1] Basov Yu.a., Pravdivtseva T.L., Snigirev A.A., Belakhovsky M., Dhez P., Freund A., Nucl. Inst. Meth. A308 (1991) 363.

[2] Chavanne J., Elleaume P., Hartmann Ya.M., Snigirev A.A., Snigireva I.I., Tarazona E., to be published in Rev. Sci. Instrum. (1994). 